\title{
Effect of Spine-Pelvis Relationship in Total Hip Arthroplasty
}

\author{
Sang Hong Lee, MD, Chae Won Lim, MD, Kwi Youn Choi, MD, Suenghwan Jo, MD \\ Department of Orthopaedic Surgery, College of Medicine, Chosun University, Gwangju, Korea
}

When spine-pelvic motion is normally coordinated, the pelvis may tilt posteriorly and acetabular anteversion may increase as the patient's position changes from standing to sitting; this scenario allows for improved clearance of the femoral head and neck during hip flexion. However, changes in the mobility of the spine and pelvis may result in impingement after total hip arthroplasty (THA), with the most obvious complication being dislocation. Understanding the spinal-pelvic relationship in the sagittal plane is essential for planning THA in patients with spinal fusion or a known spine disease. Careful attention should be payed to the cup position when performing THA on patients with an increased risk of dynamic impingement.

Key Words: Acetabular anteversion, Dislocation, Instability, Spinopelvic alignment, Hip replacement arthroplasty

\section{INTRODUCTION}

Hip instability is one of the most common causes of revision following total hip arthroplasty (THA). The dislocation rates range between $1.7 \%$ and $4.8 \%$ and redislocation rate after a first occurrence can be as high as $33 \%{ }^{1,2}$. The risk factors for dislocation can be divided into patient-related and surgery-related factors. The study by Gausden et al. ${ }^{3}$ reviewed patients who had developed dislocation following THA and noted a

Submitted: January 30, 2019 1st revision: February 11, 2019

Final acceptance: February 11, 2019

Address reprint request to

Suenghwan Jo, MD

(https://orcid.org/0000-0001-7262-710X)

Department of Orthopaedic Surgery, Chosun University Hospital,

365 Pilmundae-ro, Dong-gu, Gwangju 61453, Korea

TEL: +82-62-220-3147 FAX: +82-62-226-3379

E-mail: jo.suenghwandachosun.ac.kr

This is an Open Access article distributed under the terms of the Creative Commons Attribution Non-Commercial License (http://creativecommons. org/licenses/by-nc/4.0) which permits unrestricted non-commercial use, distribution, and reproduction in any medium, provided the original work is properly cited. history of spinal fusion surgery to be the strongest risk factor along with Parkinson's disease, depression, dementia, a history of chronic lung disease, inflammatory hip arthritis and diagnosis of avascular necrosis. In a comparative study between a group with THA after lumbar fusion and a group without, patients with a history of lumbar spinal fusion were at increased risk of dislocation ${ }^{4}$. Sultan et al. ${ }^{5}$ reported that dislocation rates ranged between $3 \%$ at 1 year and $7.5 \%$ at 2 years, exceeding the average rate, among THA patients with previous lumbar spinal fusion. Based on these findings, it can be presumed that the spino-pelvic relationship may influence the stability of THA. However, the exact mechanisms underlying this effect have not yet been fully clarified. Lewinnek et al. ${ }^{\text {) }}$ defined the safe zone for positioning of the acetabular component in THA to be inclination of $40^{\circ} \pm 10^{\circ}$ and anteversion of $15^{\circ} \pm 10^{\circ}$. However, according to the study by Murphy et al..$^{7)}$ which reviewed the cup position in patients who had developed recurrent dislocation, $32 \%$ of patients had the cup in the safe zone as described by Lewinnek et al. ${ }^{6}$. Patients who experienced unstable THA revealed that dislocation episodes commonly occur during postural changes in activities of daily living (e.g., standing up 


\section{Hip \& Pelvis}

Sang Hong Lee et al. Effect of Spine-Pelvic Relationship in Total Hip Arthroplasty

and sitting down in a chair, picking an object up off the floor). Therefore, the effect of spinopelvic interactions, which occurs during postural change, should be taken into consideration when discussing stability of the THA.

\section{SAGITTAL BALANCE AND MEASUREMENT}

Spino-pelvic alignment plays a critical role in maintaining a mechanically efficient posture. Alignment of the trunk and the pelvis relative to the hip joint is essential in achieving sagittal balance ${ }^{8}$. Since sagittal imbalance is affected by spine-related factors (e.g., a decrease in lumbar lordosis, an increase in thoracic kyphosis, pelvic parameters and joint contractures of the hip/knees), assessing spinal-pelvic parameters is essential to properly analyzing sagittal balance which has been shown to have a close correlation" ${ }^{9}$. Pelvic parameter consists of pelvic incidence (PI), pelvic tilt (PT) and sacral slope (SS), and spinal parameters include angles of lordosis and kyphosis. Lateral radiography of the spine and pelvis in the standing position is needed to measure spinal and pelvic parameters; radiographs can be obtained using a 36-inch long cassette. Recently, the EOS Imaging System (Biospace, Paris, France) using three-dimensional imaging technology has been introduced to measure the parameters more efficiently.

\section{Pelvic Incidence}

PI is the angle formed between a line perpendicular to the upper end plate of $\mathrm{S} 1$ at its midpoint and a line connecting this point to the femoral head axis (Fig. 1), and a morphological parameter that varies among individuals ${ }^{8}$. PI increases until 18 years of age and remains constant thereafter as the PT and the lumbar lordosis tend to increase with age to maintain sagittal curves during growth ${ }^{10,11}$. PI is accepted as an anatomical parameter because it equals the sum of the SS and the pelvic slope and remains constant regardless of pelvis position. When the SS increases, the PT decreases and vice versa. Additionally, PI represents a constant guide value which is unaffected by degenerative changes to the lumbar ${ }^{12}$. Normal values range from $35^{\circ}$ to $85^{\circ}$, with a mean value of $50^{\circ} \pm 10^{\circ}{ }^{13}$. According to previous studies, PI correlates with SS and lumbar lordosis ${ }^{13)}$. High PI is associated with increased lumbar lordosis and elevated SS angles. Inversely, low PI reflects less lumbar lordosis and more limited adaptability of the SS ${ }^{14,15}$. PI as an anatomical parameter of the pelvis determines the adaptability of spinopelvic balance in the sagittal plane, and low PI suggests a reduced capacity to adapt to sagittal imbalance ${ }^{15}$.
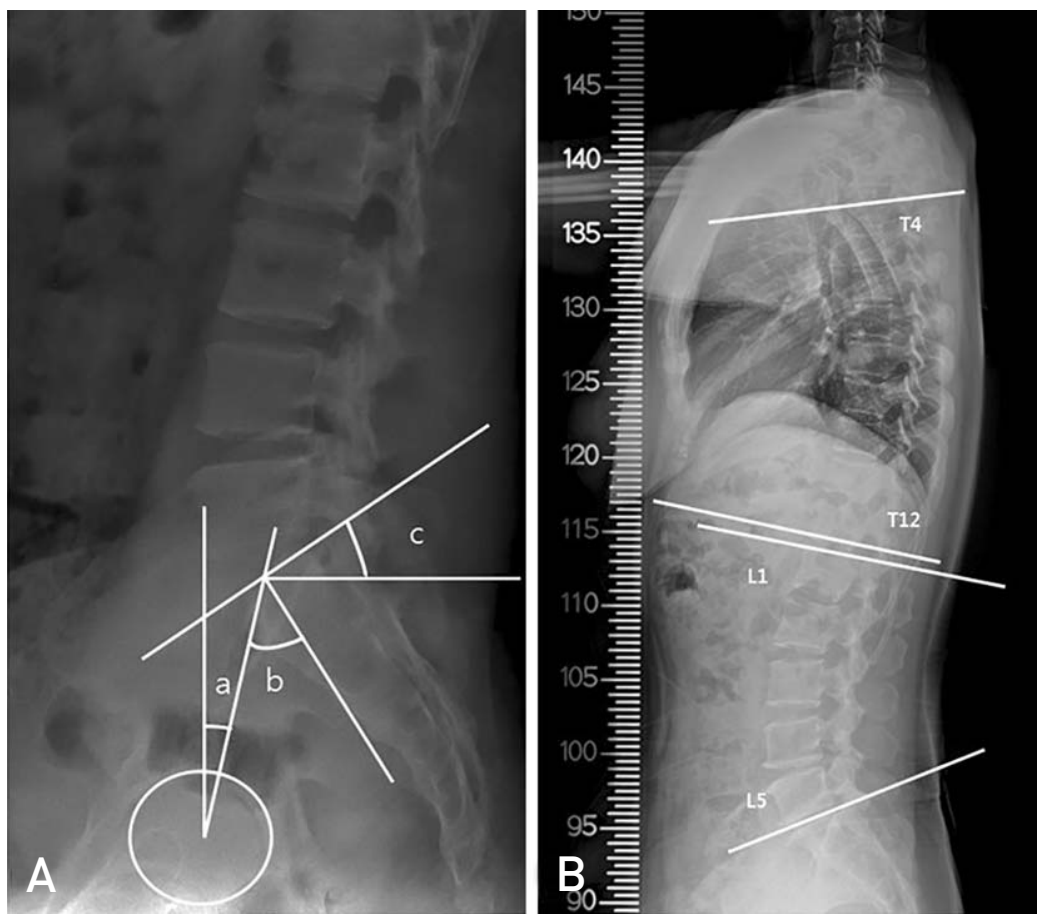

Fig. 1. Method of measurement of spino-pelvic relationship. (A) Pelvic parameter la: pelvic tlit-angle, b: pelvic incidenceangle, c: sacral slope-angle). (B) Spinal parameters. 


\section{Pelvic Tilt}

PT is the angle between the vertical line and the line joining the middle of the $\mathrm{S} 1$ endplate and the center of the femoral heads, and the normal pelvic tilt angle is $13^{\circ} \pm$ $6^{\circ}$. Unlike pelvic incidence, the value of PT changes with varied pelvic positions ${ }^{16}$. A greater PT angle is reflective of a more widely retroverted pelvis and inversely, a smaller PT indicates more anteverted pelvis ${ }^{10)}$.

\section{Sacral Slope}

SS is the angel between the upper plate of S1 and a horizontal line and the normal SS is $42^{\circ} \pm 8.5^{\circ}$. Since SS is associated with lumbar lordosis, SS angles increase with elevated lumbar lordosis. An excessively elevated SS angle causes shear forces on the lumbosacral region and may lead to lumbosacral instability and anterior dislocation $^{17)}$.

\section{Spinal Parameters}

Lumbar lordosis is the angle between the lines drawn from the upper endplate of S1 and the superior endplate of $\mathrm{L} 1$, and the normal ranges of $L L$ angles are $41^{\circ} \pm 11^{\circ}$ in males and $46^{\circ} \pm 11^{\circ}$ in females. The lower lumbar spine and lumbosacral segmental angle accounts for $2 / 3$ of the lumbar lordosis that is affected by pelvic position and angle. Thoracic kyphosis is the angle formed between the upper endplate of $\mathrm{T} 4$ and the lower endplate of $\mathrm{T} 12$, and the normal thoracic kyphosis angle is $40^{\circ} \pm$ $10^{\circ}{ }^{18)}$.

\section{SAGITTAL IMBALANCE AND COMPENSATORY MECHANISMS}

A decrease in lumbar lordosis, an increase in thoracic kyphosis, pelvic parameters and contractures of the hip/knee joints are potentially involved in sagittal imbalance. Compensatory mechanisms occur in three patterns through spine, pelvis and lower limb areas ${ }^{15,19)}$. First is the loss of lumbar lordosis caused by neurological muscle disorders in low lumbar spine, insufficient lordosis fusion and Parkinson's disease which may lead to muscle atrophy. As a compensatory mechanism for loss of lumbar lordosis, pelvic posterior rotation, hip extension, knee flexion and ankle flexion may occur. The second pattern is the anterior rotation of the pelvis and increase of SS as a compensatory for tight hip which is typical in progressive hip osteoarthritis. The third pattern is the posterior rotation of the pelvis and hip/knee flexion to compensate for excessive thoracic kyphosis when compensatory lumbar lordosis is not sufficient (Fig. 2).

\section{NORMAL SPINE-PELVIC MOTION}

As the pelvis is connected to the spine by the lumbosacral joint, the movement of the spine and the pelvis are closely related. A normal standing posture involves anterior tilt of the pelvis, lumbar lordosis and hip extension. In this position, sagittal balance is created as the trunk is located on the pelvis and the acetabulum is located above the femoral head. When changing the stance from upright standing to sitting, the hip joint does not flex to $90^{\circ}$. Instead, the pelvis tilts posteriorly by $20^{\circ}$, hip flexes about $55^{\circ}$ to $70^{\circ}$ and lumbar lordosis decreases ${ }^{20,21}$. Because the acetabulum is part of the pelvis, it will also tilt posteriorly with the pelvis during
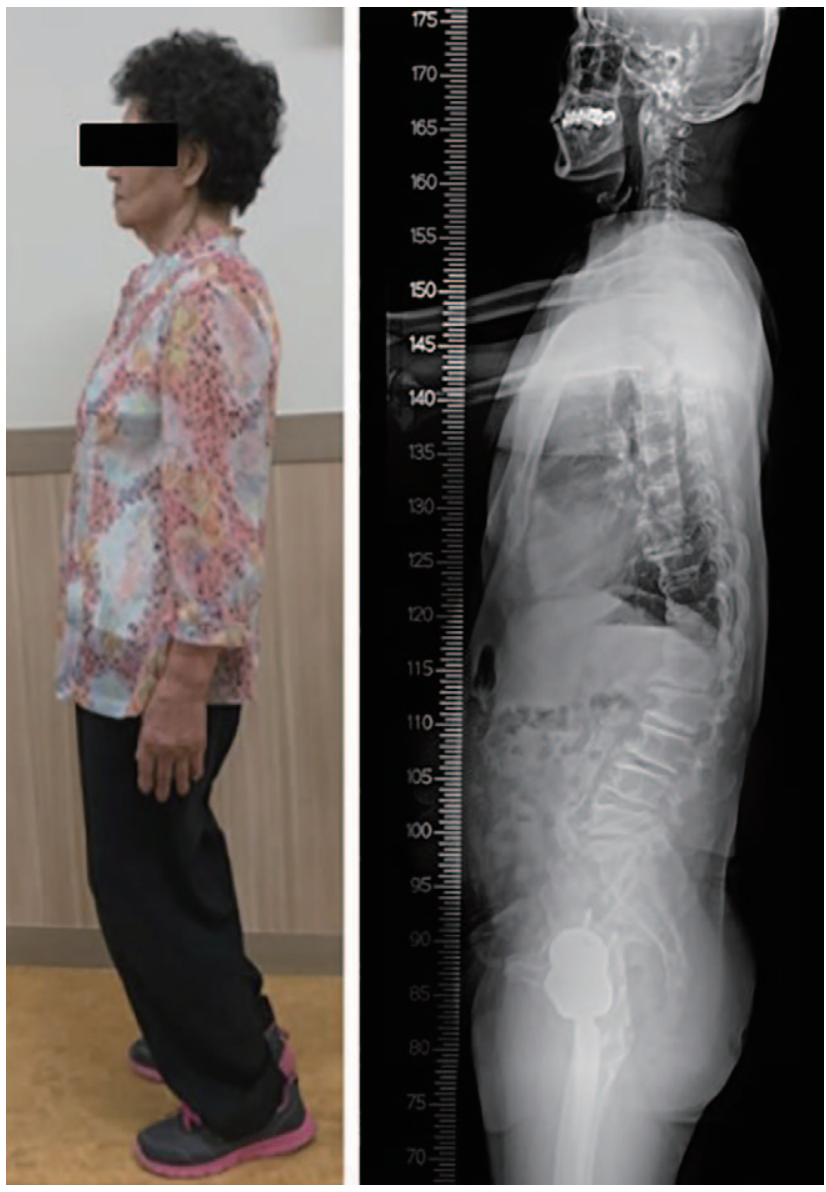

Fig. 2. Example of compensatory pelvic tilt as a result of flat back. Note the hip extension and adaptive knee flexion. 


\section{Hip \& Pelvis}

Sang Hong Lee et al. Effect of Spine-Pelvic Relationship in Total Hip Arthroplasty

sitting, leading to an increase in anteversion and inclination (Fig. 3). This change occurs to accommodate hip flexion and internal rotation and provides biologic acetabular opening ${ }^{22}$. Each degree of posterior PT leads to increase in acetabular anteversion by $0.7^{\circ 23}$. The degree of functional acetabular anteversion in the seated position can be calculated based on pelvic movement. Based on computed tomography scans, Lazennec et al. ${ }^{24)}$ reported that changing the posture from standing to sitting resulted in $20^{\circ}$ of posterior PT and $15.6^{\circ}$ increased acetabular anteversion. The term "ante-inclination" may be more suitable to describe the position of the acetabulum because acetabular anteversion in the sagittal plane on lateral spino-pelvic radiographs is affected by changes in both anteversion and inclination ${ }^{25}$. The ante-inclination ranges between $41^{\circ}$ and $63^{\circ}$ in a normal standing position. Since PT and lumbar lordosis increase by less than $3^{\circ}$ to $5^{\circ}$ in a supine position, the focus of spinopelvis motion should be on changes caused by the movement from standing to sitting ${ }^{22)}$.

\section{ABNORMAL SPINE-PELVIS MOTION}

Since spino-pelvis movement works in collaboration, a disorder in one part of the body can affect another part or parts. If one part develops limits in motion, an increase of mobility is inevitable in other regions to accommodate. An example would be an increase of motion in the upper segments after spinal fusion as a result of increased mechanical stress. The limited spinal mobility will also influence the hip, leading to increased hip flexion in the sitting position and more hip extension in the upright standing position leading to potential impingement ${ }^{20,21}$.

Abnormal spino-pelvis motion can classified into two types: hypermobility and stiffness ${ }^{26,27}$. Hypermobility is defined as a $30^{\circ}$ or greater movement of the pelvis when changing posture from upright standing to sitting. This can be viewed as part of the normal variation and is more common in younger females. Hypermobility may result in a decreased risk of hip impingement by decreasing hip motion required in posture changes. On the other hand, hypermobility caused by lumbar kyphosis is considered as imbalance. This type of kyphosis is related with three conditions. First is a condition where flexion of the hip is limited to less than $50^{\circ}$. PT increases in the sitting position in such a scenario. Second is in the obese patients with body mass index higher than $40 \mathrm{~kg} / \mathrm{m}^{2}$, where more posterior PT occurs to maintain proper posture while seated. The

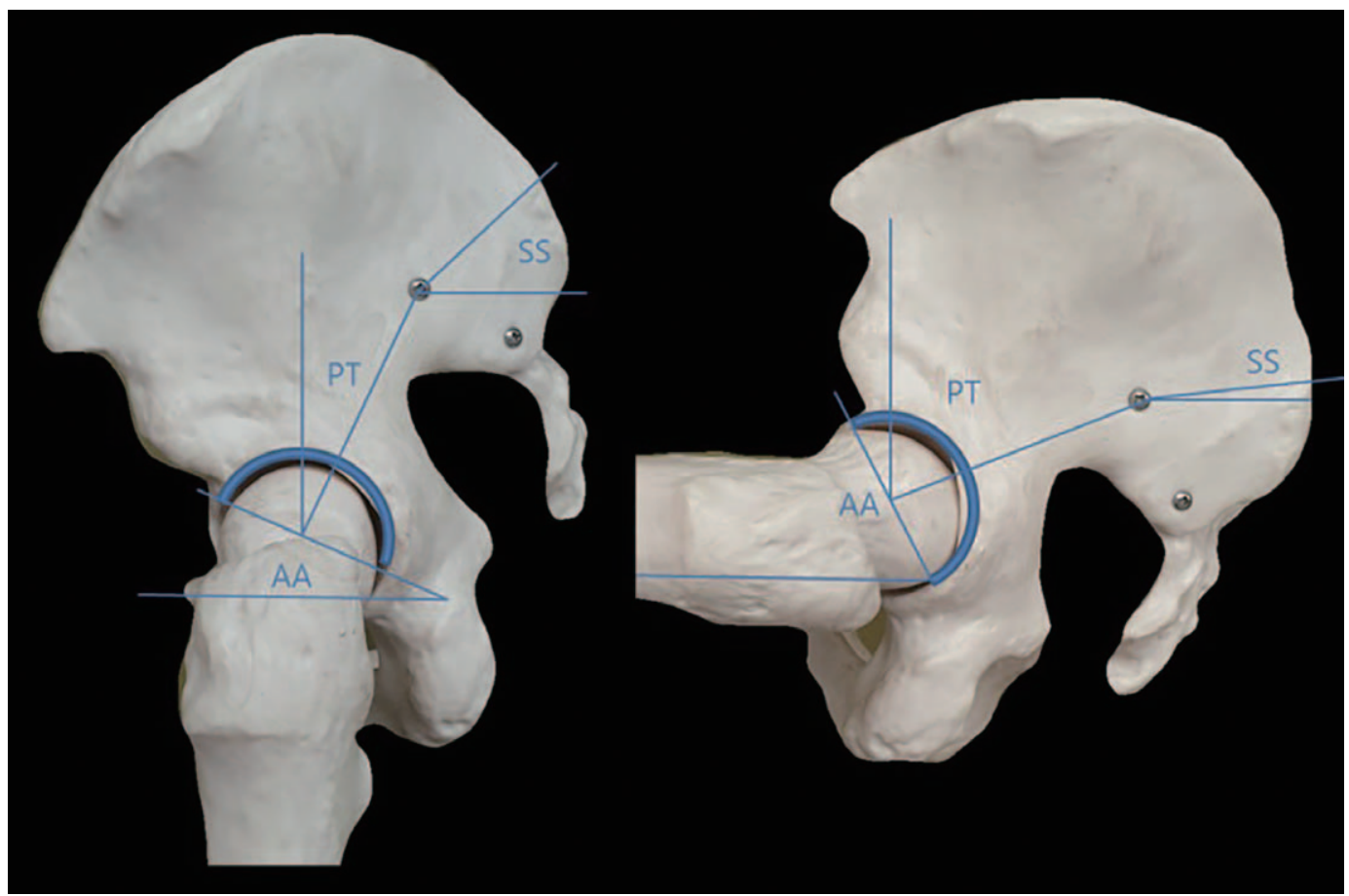

Fig. 3. Change of spine-pelvic motion in sagittal plane from standing to sitting. Pelvis tilts posteriorly in a sitting position and this result in decrease of sacral slope and increase of acetabular anteversion.

SS: sacral slope, PT: pelvic tilt, AA: acetabular anteversion. 


\section{Hip \& Pelvis}

Hip Pelvis 31(1): 4-10, 2019

third condition is neurological and muscular diseases (e.g., Parkinson' s disease $)^{21}$.

Spino-pelvic stiffness is defined as a decrease in motion of less than $10^{\circ}$ when changing the stance from upright standing to sitting; this immobility is mostly associated with degenerative conditions of the lumbar discs or lumbar fusion surgery ${ }^{20,28}$. It should be noted that degenerative changes of the spine and hip osteoarthritis commonly coexist. A previous study reported that about $21.2 \%$ to $60.4 \%$ of patients complaining of low back pain were found to have been subjected to $\mathrm{THA}^{29}$. Furthermore, approximately $40 \%$ of patients who underwent THA due to hip osteoarthritis had degenerative disease of the lumbar spine ${ }^{26}$. Stiffness can occur in all three patterns. The first pattern is characterized by decreased pelvic motion, but PT is not fixed anteriorly or posteriorly. The second pattern is loss of posterior tilt when sitting so that the pelvis is fixed in anterior tilt (sitting SS is $>30^{\circ}$ ). In the third pattern, the pelvis is fixed in posterior tilt and does not tilt anteriorly in the upright standing posture (standing SS is $<30^{\circ}$ ). High-grade stiffness of the pelvis is defined as a SS of less than $10^{\circ}$ during postural changes and these fixed patterns increase the risk of impingement and dislocation. When the spino-pelvic motion is less than $5^{\circ}$ during postural changes, this is referred to as a pathologic stiffness. The immobile spine and pelvis may create an increased risk of impingement by affecting all motion of the hip during postural changes.

\section{CLINICAL APPLICATION OF SPINE-PELVIS MOTION}

Phan et al. ${ }^{27)}$ emphasized the influence of spino-pelvic imbalance on acetabular anteversion. However, most surgeons are accustomed to analyzing the hip in standard anteroposterior radiographs which assess the acetabulum in the coronal plane. Nevertheless, since several studies revealed increased rates of dislocation following THA in patients with spinal fusion, therefore, securing safe position in the sagittal plane should be taken into consideration. McCarthy et al. ${ }^{30)}$ suggested that narrower safe zones should be permitted for cup implantation to provide stability for functional activities (e.g., bending, low sitting, and squatting). Phan et al. ${ }^{27}$ categorized spino-pelvic motion into 4 patters by reviewing sitting and standing lateral radiographs and suggested solutions to each of them. The first is flexible and balanced, which is considered to be a normal spinopelvic motion. The acetabular cup can be placed

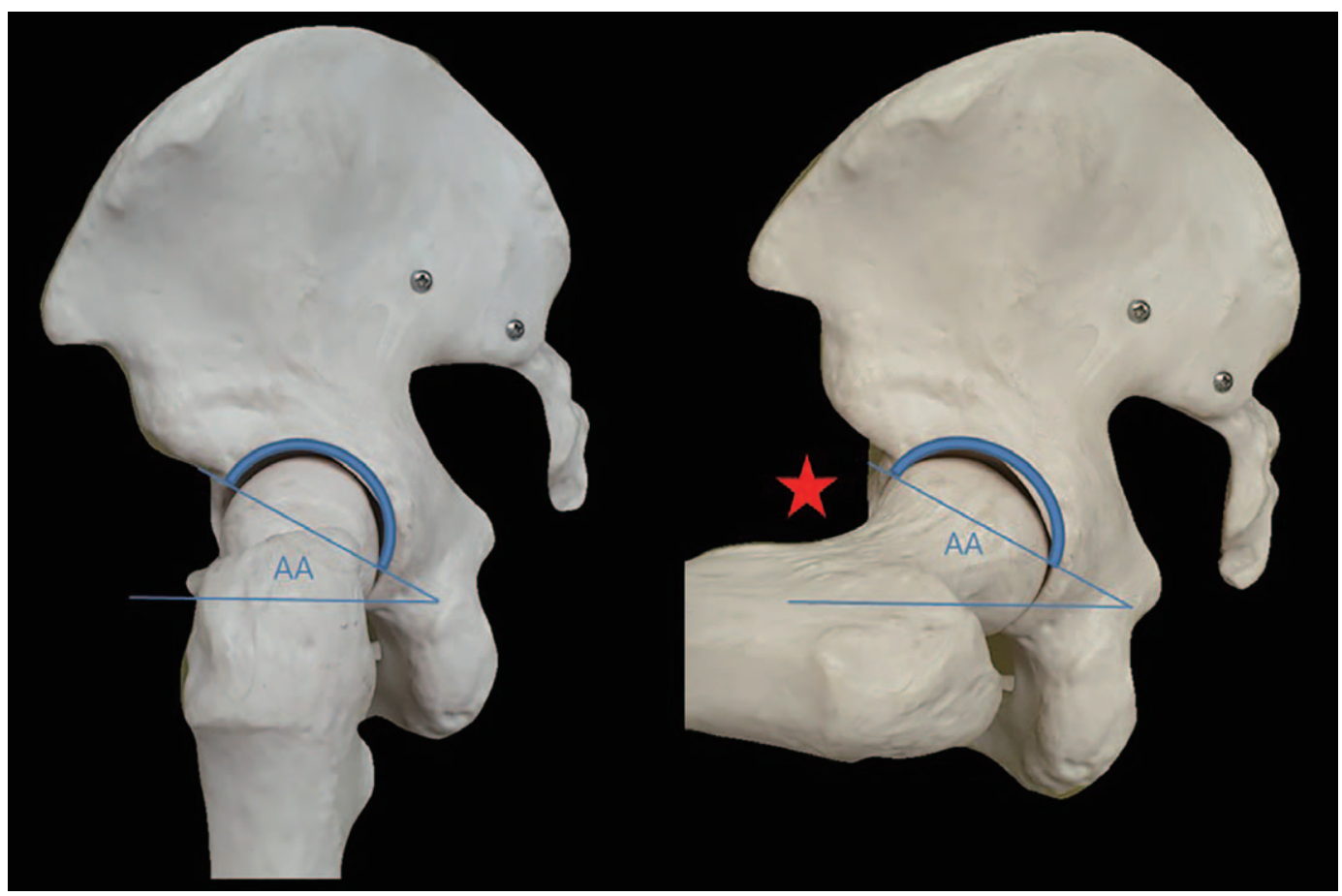

Fig. 4. Rigid and balanced type. There is no compensatory change in acetabular anteversion (AA) when going to a seated position, so possible anterior impingement when sitting. 


\section{Hip \& Pelvis}

Sang Hong Lee et al. Effect of Spine-Pelvic Relationship in Total Hip Arthroplasty

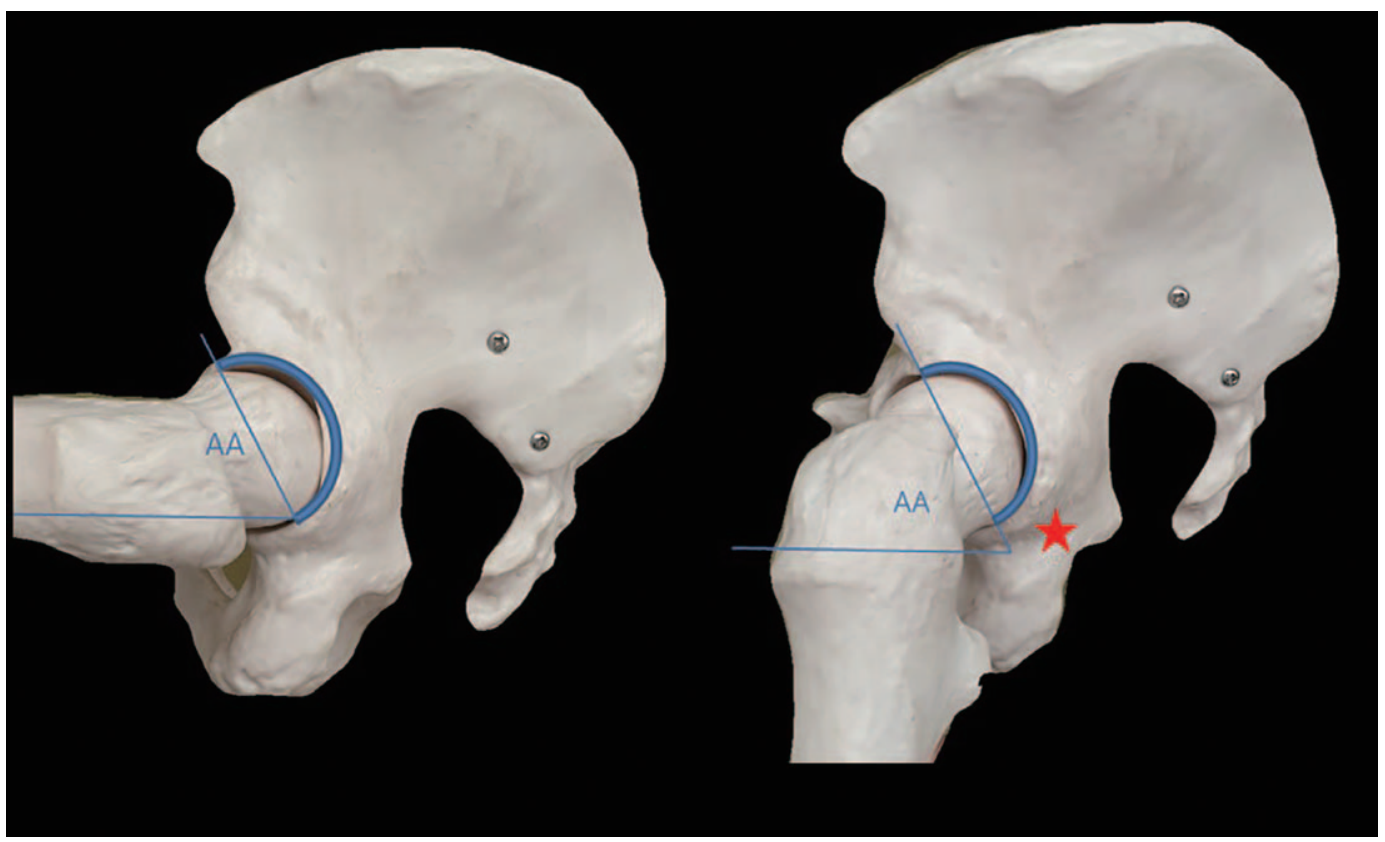

Fig. 5. Flexible and unbalanced type. In the standing position, with increased lumbar kyphosis, there is a compensatory increase in acetabular anteversion (AA). So there is possible posterior impingement when standing.

within the traditional safe zone because this pattern can be flexibly compensated by postural change. The second pattern is rigid and balanced type falling under spinopelvic stiffness which can occur after severe degenerative changes in the spine or lumbosacral fusion (Fig. 4). In patients with this pattern, compensatory acetabular anteversion increase will not occur which can lead to anterior impingement and posterior dislocation. It is better to position the cup in a more anteverted position in this scenario. The third pattern is flexible and unbalanced type that falls under hypermobility. This pattern is caused by kyphosis following laminectomy or neuromuscular disease (Fig. 5). Acetabular anteversion will increase excessively with standing and there is the potential risk of anterior dislocation due to posterior impingement during hip extension. The fourth type is rigid and unbalanced that falls under the third pattern of spinopelvic stiffness; this scenario may occur after severe stiffness of the spine and long-segment lumbosacral fusion. Patients with this pattern may develop kyphotic flat back and increased acetabular anteversion. The risk of anterior dislocation increases due to posterior impingement, despite no anterior PT in the standing position. There are two treatment options for the management of the third and fourth types. One would be changing flexible and unbalanced type to rigid and balanced type via correction of spinal deformity before THA. The other option is to reduce acetabular anteversion appropriate for each patient.

\section{CONCLUSION}

When performing THA, understanding the spino-pelvic relationship is important to minimize postoperative instability. Radiography of the lateral spine and hip views should be performed in the standing and sitting positions when planning THA. Surgeons should pay closer attention to the cup position in patients with a spinopelvic imbalance. Care to better understand the cup position is required as there is an increased rate of dislocation in patients with lumbar spinal fusion.

\section{CONFLICT OF INTEREST}

The authors declare that there is no potential conflict of interest relevant to this article.

\section{ACKNOWLEDGEMENTS}

This study was supported by research fund from Chosun University, 2017. 


\section{REFERENCES}

1. Khatod M, Barber T, Paxton E, Namba R, Fithian D. An analysis of the risk of hip dislocation with a contemporary total joint registry. Clin Orthop Relat Res. 2006;447:19-23.

2. Berry DJ. Unstable total hip arthroplasty: detailed overview. Instr Course Lect. 2001;50:265-74.

3. Gausden EB, Parhar HS, Popper JE, Sculco PK, Rush BNM. Risk factors for early dislocation following primary elective total hip arthroplasty. J Arthroplasty. 2018;33:1 567-71.e2.

4. Malkani AL, Garber AT, Ong KL, et al. Total hip arthroplasty in patients with previous lumbar fusion surgery: are there more dislocations and revisions? J Arthroplasty. 2018;33:1189-93.

5. Sultan AA, Khlopas A, Piuzzi NS, Chughtai M, Sodhi N, Mont MA. The impact of spino-pelvic alignment on total hip arthroplasty outcomes: a critical analysis of current evidence. J Arthroplasty. 2018;33:1606-16.

6. Lewinnek GE, Lewis JL, Tarr R, Compere CL, Zimmerman JR. Dislocations after total hip-replacement arthroplasties. J Bone Joint Surg Am. 1978;60:217-20.

7. Murphy WS, Yun HH, Hayden B, Kowal JH, Murphy SB. The safe zone range for cup anteversion is narrower than for inclination in THA. Clin Orthop Relat Res. 2018;476: 325-35.

8. Duval-Beaupére G, Schmidt C, Cosson P. A Barycentremetric study of the sagittal shape of spine and pelvis: the conditions required for an economic standing position. Ann Biomed Eng. 1992;20:451-62.

9. Legaye J, Duval-Beaupére G, Hecquet J, Marty C. Pelvic incidence: a fundamental pelvic parameter for threedimensional regulation of spinal sagittal curves. Eur Spine J. 1998;7:99-103.

10. Mac-Thiong JM, Berthonnaud E, Dimar JR 2nd, Betz RR, Labelle H. Sagittal alignment of the spine and pelvis during growth. Spine (Phila Pa 1976). 2004;29:1642-7.

11. Vaz G, Roussouly P, Berthonnaud E, Dimnet J. Sagittal morphology and equilibrium of pelvis and spine. Eur Spine J. 2002;11:80-7.

12. Barrey C, Jund J, Noseda O, Roussouly P. Sagittal balance of the pelvis-spine complex and lumbar degenerative diseases. A comparative study about 85 cases. Eur Spine J. 2007; 16:1459-67.

13. Schwab F, Patel A, Ungar B, Farcy JP, Lafage V. Adult spinal deformity-postoperative standing imbalance: how much can you tolerate? An overview of key parameters in assessing alignment and planning corrective surgery. Spine (Phila Pa 1976). 2010;35:2224-31.

14. Gelb DE, Lenke LG, Bridwell KH, Blanke K, McEnery KW. An analysis of sagittal spinal alignment in 100 asymptomatic middle and older aged volunteers. Spine (Phila Pa 1976). 1995;20:1351-8.

15. Boulay C, Tardieu C, Hecquet J, et al. Sagittal alignment of spine and pelvis regulated by pelvic incidence: standard values and prediction of lordosis. Eur Spine J. 2006;15: 415-22.

16. Jackson RP, McManus AC. Radiographic analysis of sagittal plane alignment and balance in standing volunteers and patients with low back pain matched for age, sex, and size. A prospective controlled clinical study. Spine (Phila Pa 1976). 1994;19:1611-8.

17. Rajnics P, Templier A, Skalli W, Lavaste F, Illés T. The association of sagittal spinal and pelvic parameters in asymptomatic persons and patients with isthmic spondylolisthesis. J Spinal Disord Tech. 2002;15:24-30.

18. Roussouly P, Gollogly S, Noseda O, Berthonnaud E, Dimnet J. The vertical projection of the sum of the ground reactive forces of a standing patient is not the same as the $C 7$ plumb line: a radiographic study of the sagittal alignment of 153 asymptomatic volunteers. Spine (Phila Pa 1976). 2006;31:E320-5.

19. Legaye J, Duval-Beaupere G, Barrau A, et al. Relationship between sacral pelvic incidence and acetabular orientation. Hip Int. 2011;21:87-97.

20. Lazennec JY, Charlot N, Gorin M, et al. Hip-spine relationship: a radio-anatomical study for optimization in acetabular cup positioning. Surg Radiol Anat. 2004;26: 136-44.

21.Lazennec JY, Riwan A, Gravez F, et al. Hip spine relationships: application to total hip arthroplasty. Hip Int. 2007; 17 Suppl 5:S91-S104.

22. Ike H, Dorr LD, Trasolini N, Stefl M, McKnight B, Heckmann N. Spine-pelvis-hip relationship in the functioning of a total hip replacement. J Bone Joint Surg Am. 2018;100:1606-15.

23. Wan Z, Malik A, Jaramaz B, Chao L, Dorr LD. Imaging and navigation measurement of acetabular component position in THA. Clin Orthop Relat Res. 2009;467:32-42.

24. Lazennec JY, Boyer P, Gorin M, Catonné Y, Rousseau MA. Acetabular anteversion with CT in supine, simulated standing, and sitting positions in a THA patient population. Clin Orthop Relat Res. 2011;469:1103-9.

25. Kanawade V, Dorr LD, Wan Z. Predictability of acetabular component angular change with postural shift from standing to sitting position. J Bone Joint Surg Am. 2014;96:978-86.

26. Stefl M, Lundergan W, Heckmann N, et al. Spinopelvic mobility and acetabular component position for total hip arthroplasty. Bone Joint J. 2017;99-B (1 Supple A):37-45.

27. Phan D, Bederman SS, Schwarzkopf R. The influence of sagittal spinal deformity on anteversion of the acetabular component in total hip arthroplasty. Bone Joint J. 2015; 97-B:1017-23.

28. Philippot R, Wegrzyn J, Farizon F, Fessy MH. Pelvic balance in sagittal and Lewinnek reference planes in the standing, supine and sitting positions. Orthop Traumatol Surg Res. 2009;95:70-6.

29. Staibano P, Winemaker M, Petruccelli D, de Beer J. Total joint arthroplasty and preoperative low back pain. J Arthroplasty. 2014;29:867-71.

30. McCarthy TF, Alipit V, Nevelos J, Elmallah RK, Mont MA. Acetabular cup anteversion and inclination in hip range of motion to impingement. J Arthroplasty. 2016;31(9 Suppl):264-8. 